\begin{tabular}{|c|l|}
\hline Title & Establishment and characterization of turbine oil-degrading bacterial consortia \\
\hline Author(s) & Hosokawa, Reia; Sakaguchi, Naofumi; Okuyama, Hidetoshi \\
\hline Citation & $\begin{array}{l}\text { International Biodeterioration \& Biodegradation, 64(6), 519-524 } \\
\text { https://doi.org/40.1016/.ibiod.2010.06.006 }\end{array}$ \\
\hline Issue Date & 2010-09 \\
\hline Doc URL & http://hdl.handle.net/2115/43801 \\
\hline Type & article (author version) \\
\hline File Information & IBB646_519-524.pdf \\
\hline
\end{tabular}

Instructions for use 


\title{
Establishment and Characterization of Turbine Oil-Degrading Bacterial Consortia
}

\author{
Reia Hosokawa, ${ }^{\mathrm{a}}$ Naofumi Sakaguchi, ${ }^{\mathrm{b}}$ and Hidetoshi Okuyama, ${ }^{\mathrm{a}, \mathrm{b}, \text {,* }}$
}

${ }^{a}$ Course in Environmental Molecular Biology and Microbial Ecology, Division of Biosphere

Science, Graduate School of Environmental Science, Hokkaido University, Kita-ku, Sapporo 060-0810, Japan

${ }^{\mathrm{b}}$ Department of Biological Science, Faculty of Science, Hokkaido University, Kita-ku, Sapporo 060-0810, Japan

' Laboratory of Environmental Molecular Biology, Faculty of Environmental Earth Science, Hokkaido University, Kita ku, Sapporo 060-0810, Japan

Keywords: Bacterial consortia; Bacterial aggregates; Bioremediation; Branched alkanes; Cyclic alkanes; Turbine oil (TuO)

Corresponding author. Faculty of Environmental Earth Science, Hokkaido University, Sapporo 060-0810, Japan. Tel.: +81 11706 4523; fax: +81 117062347.

E-mail address: hoku@ees.hokudai.ac.jp (H. Okuyama). 


\section{Abstract}

A microbial consortium capable of degrading turbine oil (TuO) consisting mainly

of recalcitrant branched and polycyclic alkanes, has been established using a sludge

sample collected from an oil-water separation tank of a hydraulic plant, by repeated

enrichment cultivation. When this consortium, named the tank-2 consortium, was

cultivated in a minimal salts medium containing $0.5 \%$ TuO, it degraded approximately

$90 \%$ of TuO at $30{ }^{\circ} \mathrm{C}$ under shaking at $160 \mathrm{rpm}$ in five days. During cultivation, the

consortium formed cell aggregates. Fourteen bacterial species were isolated from the

consortium. Although the mixtures of all of the isolated strains (IM) and predominant

strains selected from the IM (PM) degraded approximately $60 \%$ of the TuO maximally

in seven days after repeated enrichment, the degradation rate was not maintained. The

decreased rate of TuO degradation in the PM was recovered by inoculation with a

mixture (AM) consisting of isolates involved in the cell aggregate formation in the 
tank-2 consortium, suggesting that the formation of bacterial aggregates is an important factor for the degradation of TuO by the bacterial consortia. Interestingly, the formation of bacterial aggregates was only observed when cyclic alkanes were added to the consortium as a source of carbon. The cell surface hydrophobicity of the bacterial aggregates was significantly high $(77.6 \%)$. These results suggest that the growth of bacteria with high cell hydrophobicity can be induced by the cyclic alkanes fraction of TuO, and that the formation of aggregates facilitates cells to form contact with the recalcitrant components of TuO and uptakes these components.

\section{Introduction}

Turbines are an equipment necessary to convert physical energy to electrical energy, and are installed in various industrial facilities. For smooth and efficient functioning, turbine oils (TuOs) are used as lubricating oils. Lubricating oils contain a 'base oil' mixture 
consisting mainly of branched and cyclic alkanes, along with some additives (Komiya 1997). According to Perry (1984), cyclic alkanes are recalcitrant to microbial degradation compared with linear alkanes and aromatic hydrocarbons. Thus, even if the extent of contamination by $\mathrm{TuO}$ at each site is low and if spills of TuOs occur infrequently, when compared with oils such as crude oil and heavy oil, the released TuO remains and accumulates in the environment for extended periods due to its poor biodegradability.

In a previous study (Ito et al. 2008), we obtained a bacterial consortium (named Atsuta A consortium) from an oil field, and it degraded $90 \%$ of the TuO at $30{ }^{\circ} \mathrm{C}$ after a period of five days. However, any efficient strain that degrades TuO has never been isolated using minimal salts medium (MSM) agar plates supplemented with TuO. Therefore, the mechanism of TuO degradation, the roles of individual bacterial strains in the consortium, and their interactions are still unknown.

To isolate the bacterial strains involved in the degradation of $\mathrm{TuO}$ and to understand the participation of individual isolates in TuO degradation, we established a new TuO- 
degrading consortium and improved an medium composition for the isolation of bacterial strains. First, we established a consortium (the tank-2 consortium) using a wastewater sample from a hydraulic plant and an MSM supplemented with TuO by repeated enrichment cultivations. Second, we layered cyclic and branched alkanes individually other than $\mathrm{TuO}$ to MSM agar plates, to isolate the strains that are able to degrade TuO and certain types of hydrocarbon. Third, nutrient-rich Luria-Bertani medium (LB) plates were also used to isolate strains that may not be involved in the degradation of TuO directly but could play important roles in the TuO degradation mechanism. The combined use of LB plates and various petroleum products layered on the plates was expected to isolate strains capable of degrading hydrocarbons and other organic nutrients.

The aims of this study are: (i) to establish a TuO-degrading bacterial consortium and (ii) to elucidate the roles of individual isolates and their involvement in the degradation of $\mathrm{TuO}$ to understand the mechanism, by which TuO is degraded. 


\section{Materials and methods}

\subsection{Petroleum products and media}

TuO (type, FBK turbine SH), a product of Nippon Oil Corporation (Tokyo, Japan), was donated by the Hokkaido Electric Power Co., Inc., car engine oil (type, Castrol XLX; abbreviated as EO) was obtained from the Castrol Company (Tokyo). Arabian light crude oil (denoted as crude oil) was gifted from Idemitsu Kosan Company (Tokyo). Squalane (2,6,10,15,19,23-hexamethyltetracosane; SQ) and dodecylcyclohexane (DC) were

purchased from the Tokyo Kasei Kogyo Company (Tokyo). Pristane (2,6,10,14tetramethylpentadecane; PR) was obtained from the Wako Pure Chemical Industries (Osaka, Japan). The chemical composition of the TuO was an industrial secret of the Nippon Oil Coorporation. The only information available on this oil was that approximately $65 \%(\mathrm{w} / \mathrm{w})$ 
of the base oil was cyclic alkanes (Ito et al. 2008).

The TuO, EO, SQ and crude oil were sterilized by autoclaving at $121{ }^{\circ} \mathrm{C}$ for $20 \mathrm{~min}$. The other petroleum products were sterilized by filtration using a filter (type, Millex, pore size of $0.22 \mu \mathrm{m}$; Millipore, Bedford, MA, USA). Each petroleum product was added to a minimal salts medium (MSM) at a final concentration of $0.5 \%(\mathrm{w} / \mathrm{v})$. The MSM consisted of $0.4 \%(w / v) ~ \mathrm{NH}_{4} \mathrm{NO}_{3}, 0.47 \%$ (w/v) $\mathrm{KH}_{2} \mathrm{PO}_{4}, 0.0119 \%$ (w/v) $\mathrm{NaHPO}_{4}, 0.001 \%$ (w/v) $\mathrm{CaCl}_{2} \cdot 2 \mathrm{H}_{2} \mathrm{O}, 0.1 \%$ (w/v) $\mathrm{MgSO}_{4} \cdot 7 \mathrm{H}_{2} \mathrm{O}, 0.001 \%$ (w/v) $\mathrm{MnSO}_{4} \cdot 4 \mathrm{H}_{2} \mathrm{O}$, and $0.0015 \%$ (w/v)FeSO ${ }_{4} \cdot 4 \mathrm{H}_{2} \mathrm{O}, \mathrm{pH} 7.0$ (Wongsa et al. 2004).

\subsection{Fractionation of TuO}

The cyclic alkanes were fractionated from the TuO by the method of Lappas et al. (1997) with slight modifications. Briefly, $50 \mathrm{ml}$ of methanol and $30 \mathrm{~g}$ of urea were added to

$10 \mathrm{~g}$ of $\mathrm{TuO}$, and shaken at $160 \mathrm{rpm}$, for $30 \mathrm{~min}$ at $55^{\circ} \mathrm{C}$, for $1.5 \mathrm{~h}$ at room temperature, and 
for $30 \mathrm{~min}$ at $10^{\circ} \mathrm{C}$. After filtered using a glass funnel (300 ml glass funnel, Millipore Corporation, Billerica, MA), $30 \mathrm{~g}$ of thiourea was added to the filtrates and shaken for $2 \mathrm{~h}$ at room temperature. The mixture was then filtered using a glass funnel. The crystals contained a branched alkane fraction. A cyclic alkane fraction contained in the filtrates was extracted using $60 \mathrm{ml}$ of hexane. The hexane solution of cyclic alkanes was evaporated using a rotary evaporator.

\subsection{Enrichment of the TuO-degrading bacterial consortia}

Wastewater, including the sludge of the oil-water separation tank, was collected at the

Moiwa hydraulic plant located at Minami-ku, Sapporo, Japan, where TuO is routinely used.

The sample was named “tank-2". To enrich the microorganisms capable of utilizing TuO,

$500 \mathrm{ml}$ of the tank-2 sample was centrifuged at 5,000 $\times \mathrm{g}$ for $10 \mathrm{~min}$ to precipitate any insoluble matter. The pellets were suspended in $10 \mathrm{ml}$ of the supernatant liquid and then 
inoculated to a $50 \mathrm{ml}$ flask that contained $10 \mathrm{ml}$ of MSM supplemented with $0.5 \%(\mathrm{w} / \mathrm{v})$

TuO. The culture was then incubated at $30{ }^{\circ} \mathrm{C}$ on a rotary shaker $(160 \mathrm{rpm})$ for two weeks

(designated the first enrichment culture). During the cultivation, bacterial cultures formed

aggregates. A small block of these bacterial aggregates (approximately $2 \mathrm{~mm} \times 4 \mathrm{~mm} \times 1$

$\mathrm{mm}$ ) was collected using an inoculation loop and was transferred to a fresh MSM medium

containing TuO. At the same time, $200 \mu \mathrm{l}$ of liquid culture was also transferred. This second

enrichment culture was subsequently transferred to the TuO-containing medium and cultivated under the same conditions.

\subsection{Degradation tests}

To test the degradation of TuO by the tank-2 consortium, a block of bacterial aggregates and $200 \mu \mathrm{l}$ of the culture liquid collected from the individual enrichment cultures

(tank-2 consortia) grown at $30{ }^{\circ} \mathrm{C}$ for two weeks were inoculated directly into $10 \mathrm{ml}$ of 
MSM supplemented with $0.5 \%(\mathrm{w} / \mathrm{v})$ TuO. These cultures were incubated at $30{ }^{\circ} \mathrm{C}$ with shaking for the indicated time, and the remaining petroleum product was quantified, as described below. When isolates from the tank-2 consortium or various types of their artificial mixture (IM, PM, and AM; see below and Table 1) were used, individual isolates were cultivated in $\mathrm{LB}$ medium at $30^{\circ} \mathrm{C}$ for one day and the mixture that contained an equal number of cells of each isolate was used as the inoculum. Cultures of isolates and their mixture precultivated in LB medium were transferred to MSM containing 0.5\% (w/v) TuO. The initial optical density at $600 \mathrm{~nm}\left(\mathrm{OD}_{600}\right)$ of the inocula was set at 0.1 . These cultures were incubated at $30{ }^{\circ} \mathrm{C}$ for the indicated time with shaking at $160 \mathrm{rpm}$ and the residual TuO was quantified. Three independent determinations were made for each sample.

2.6. Isolation of bacterial strains from the tank-2 consortium

To isolate bacterial strains, $50 \mu \mathrm{l}$ aliquots of the culture were spread onto either MSM 
or LB plates that contained 1.5\% (w/v) agar, on which one of the petroleum products (TuO,

EO, SQ, DC, PR, DC, crude oil, or the cyclic alkane fraction of TuO) was spread. The

plates were then incubated at $30{ }^{\circ} \mathrm{C}$. To purify the individual strains, they were streaked at

least four times onto agar plates having the same composition.

2.7. Analysis of total petroleum hydrocarbons

The total petroleum hydrocarbon (TPH) content was analyzed by the thin-layer chromatography-flame ionization detection (TLC-FID) method on an Iatroscan (type MK-

6, Mitsubishi Kagaku Iatron, Tokyo), as described previously (Ito et al. 2008).

2.8. Bacterial adherence to hydrocarbon analysis

The hydrophobicity of the cell aggregates and the free-living cells of the tank-2 
consortium was determined by the bacterial adherence to hydrocarbon (BATH) method

(Rosenberg et al. 1980). Aggregates were recovered from the consortium with the inoculating loop sterilized in flame, and the cells remaining in the culture liquid (free-living cells) were collected by centrifugation $(1,500 \times \mathrm{g}, 10 \mathrm{~min})$. Both the aggregates and the free-living cells were washed twice with $50 \mathrm{mM}$ HEPES buffer and resuspended with the same buffer to give an $\mathrm{OD}_{600}$ of 1.0. The cell suspension $(1.8 \mathrm{ml})$ was layered with $300 \mu \mathrm{l}$ hexadecane and then vortex-shaken for two min after $10 \mathrm{~min}$ incubation at $30{ }^{\circ} \mathrm{C}$. For 15 min after shaking, the hexadecane and aqueous phases were allowed to separate. The hydrophobicity was expressed as a percentage of the adherence of cells to hexadecane and calculated as $100 \times\left(1-\mathrm{OD}_{600}\right.$ of the aqueous phase/OD 600 of the initial cell suspension $)$.

\subsection{DNA procedures.}

The bacterial cells were harvested by centrifugation at $3,500 \times \mathrm{g}$ at $4{ }^{\circ} \mathrm{C}$ for $10 \mathrm{~min}$. 
The pellets were freeze-dried overnight. The DNA was extracted from the dried cells, as described previously (Ito et al. 2008). To determine the whole sequence of the 16S rRNA gene, PCR was carried out using DNA fragments corresponding to positions 9-27 and 1525-1541 of the 16S rRNA gene sequence of Escherichia coli as primers (Brousius et al. 1978) and DNA of isolated strains as templates, as described by Ito et al. (2008). For denaturing gradient gel electrophoresis (DGGE), PCR was carried out using a set of primers with a GC clamp corresponding to the V3 regions of the 16S rRNA gene sequence (Ito et al. 2008). The PCR reaction mixture (final volume of $50 \mu \mathrm{l}$ ) included one unit of Ex Taq DNA polymerase (TaKaRa BIO, Shiga, Japan), $200 \mathrm{nM}$ of a dNTP mixture, 25 pM of each primer, $1 \times$ PCR reaction buffer, and genomic DNA as template. PCR cycles were initiated at $94{ }^{\circ} \mathrm{C}$ for $5 \mathrm{~min}$ followed by 30 cycles of $1 \mathrm{~min}$ at $94{ }^{\circ} \mathrm{C}, 1 \mathrm{~min}$ at $55^{\circ} \mathrm{C}$ and 1 or $2 \mathrm{~min}$ at $72{ }^{\circ} \mathrm{C}$, according to the length of amplification. The PCR cycles were concluded with a 5 min extension at $72{ }^{\circ} \mathrm{C}$.

DGGE was performed on a D-code ${ }^{\mathrm{TM}}$ Universal Mutation Detection system (Bio-Rad 
Laboratories, CA, USA). The PCR products (10 $\mu$ l each) were mixed with $2 \mu$ of alkaline gel-loading buffer containing $300 \mathrm{mM} \mathrm{NaOH,} 6$ mM EDTA, 18\% (w/v) Ficoll, and 0.25\% (w/v) xylene cyanol, and then this was loaded on an acrylamide gel containing a denaturant urea-formamide gradient ranging from 20\% to 60\% (Muyzer et al. 1993). Electrophoresis was performed at a constant voltage of $200 \mathrm{~V}$ for $3 \mathrm{~h}$ at a constant temperature of $60{ }^{\circ} \mathrm{C}$. After running, gel was stained for $30 \mathrm{~min}$ in $0.5 \times$ TAE containing $1 \times$ SYBR Green (BioWhittaker, Walkersville, MD) and photographed under UV illumination.

The DNA inserted into the $\mathrm{pCR}^{\circledR} 2.1 \mathrm{TOPO}^{\circledR}$ vector (Invitrogen, CA) was amplified using the BigDye terminator v3.1 Cycle Sequencing Kit (Applied Biosystems, Tokyo) following the manufacturer's instructions, and the nucleotide sequences were analyzed by an ABI PRISM 3100 Genetic Analyzer (Applied Biosystems Japan), as described previously (Ueno et al. 2006). The nucleotide sequences were analyzed by searching the GenBank using the Blast program (http://www.ncbi.nlm.nih.gov/BLAST/). 


\section{Results and discussion}

\subsection{Establishment of the TuO-degrading bacterial consortia}

A bacterial consortium was established by enrichment cultivation in MSM containing

$\mathrm{TuO}$ and designated the tank-2 consortium. The tank-2 consortium formed bacterial aggregates. The levels of TuO degradation by the tank- 2 consortium gradually increased and reached up to value of $88 \%$ in five days, when the sixth enriched culture was used as the inoculum (Table 1). The degradation and aggregate-forming capacities of the tank-2 consortium, which had almost the same microbial community structure (see below), were maintained throughout the subsequent enrichment steps. The formation of similar aggregates during TuO degradation by a bacterial consortium was reported by Ito et al. (2008), implying that this may be related to efficient degradation of TuO by bacterial 
consortia.

3.2. Isolation of bacterial isolates from the tank-2 consortium and their PCR-DGGE analysis

Although 12 bands were detected in the PCR-DGGE analysis of the tank-2 consortium

(Fig. 1A), 14 strains, labeled a to n, were isolated using two types of agar plates (MSM and

LB), on which various types of petroleum product were layered. Plates without layered petroleum products were also used for LB plates. Isolates with the same DGGE band profiles were regarded as being the same strains. Strains a, e, f, g, h, l, and m had multiple DGGE bands and the multiple DGGE band profiles of these strains were unchanged, even after plating more than four times. These results suggest that purification had not been achieved for these isolates, or that all or some of them may have had multiple copies of the 16S rRNA-encoding gene. Strains a and b were isolated using LB plates without any 
petroleum layered. Strains c, d, and e were isolated using LB plates layered with TuO.

Strains $\mathrm{f}$ and $\mathrm{g}$ and strain $\mathrm{h}$ were isolated using LB plate with $\mathrm{DC}$ and PR, respectively.

Strains $i$ and $j$ were isolated using LB plates with the cyclic alkane fraction of TuO. Strains

$\mathrm{k}, \mathrm{l}$, and $\mathrm{m}$ and strain n were isolated using MSM plate with TuO and crude oil, respectively.

According to Klappenbach et al. (2000), bacteria capable of utilizing diverse substrates for

growth substrate had more copies of the 16S rRNA gene than bacteria able to utilize only

limited substrate. Interestingly, all of the strains isolated in this study could grow in liquid

LB. Considering that the organic nutrient components in the LB and cyclic and branched

alkanes are different chemical substances, bacterial strains, such as strains e, g, h, l, and m

in Table 2, which utilized both hydrocarbons and LB as substrates, may have multiple 16S

rRNA genes. The DGGE bands of strains $b, i, l$, and $n$ did not correspond to any band

derived from the tank-2 consortium (Fig. 1A). Isolated strains, the types of agar plate and

petroleum products used to isolate each strain, and its corresponding band(s) detected in the tank-2 consortium are summarized in Table 2. 
3.3. Degradation of TuO by isolates from the tank-2 consortium and their mixtures

The degradation rate of TuO by each isolate was much lower than that of the tank- 2

consortium (data not shown), and the first enrichment culture of the mixture (IM) of all 14

isolates degraded only 6\% of the TuO in MSM (Table 1). The degradation rate of TuO by

the IM mixture gradually increased and reached approximately $65 \%$ at the fourth

enrichment cultivation. However, the rate decreased after the fourth enrichment, and

reached approximately $15 \%$ at the seventh enrichment (Table 1). A similar trend was

observed in PM, a mixture of four selected predominant strains (strains d, e, g, and m) of

IM (Table 1). These results suggest that all or some strains involved in the TuO degradation

are included in the IM and PM mixtures, and that an appropriate bacterial community

structure is required for TuO degradation. Sonderkamp et al. (2001) reported that the secretion of exoenzymes promoted the metabolism of trimethylpropaneoleate in a bacterial 
community, which suggests that some strains may only exhibit a capacity to degrade TuO,

when some essential substances, such as extracellular enzymes, were provided by other

bacterial strains in the community

Interestingly, four strains of the PM mixture were tentatively identified as being

different strains of Pseudomonas putida (Table 3). Pseudomonas species are known as fast-

growing bacteria, which rapidly grow under laboratory conditions (Sayler and Ripp 2000).

Since the IM mixture contained an equal cell number of 14 isolates (having the same optical density of each culture), it is suggested that these fast-growing strains became predominant in the early stage of enrichment, which may prohibit the growth of TuO-degrading bacteria.

\subsection{Selection of isolates involved in the formation of bacterial aggregates}

The formation of bacterial aggregates did not occur during repeated cultivations of the

IM mixture in TuO-containing MSM (data not shown). This was significantly different from 
the case of the tank-2 consortium.

The bacterial community structures of the IM mixture and the cell aggregates formed

by the tank-2 consortium were compared to investigate the relationship between the formation of bacterial aggregates and the degradation of TuO. The DGGE banding profiles of the aggregates and free-living cell fractions were quite different (lanes 3 and 4 in Fig. 2B). The IM did not include any bands corresponding to those detected in the aggregates (bands 6, 8, and 10), implying that the strains involved in aggregate formation were not predominant in the IM. These results suggest that the bacterial strains corresponding to DGGE bands 6, 8, and 10 are involved in the formation of aggregates.

\subsection{Establishment of an isolates mixture that consistently degraded TuO}

The strains corresponding to DGGE bands 6,8 , and 10 were considered to be strains $\mathrm{j}$,

f, and c, respectively (Figs. 1A and 1B). Strain c was tentatively identified as Sinorhizobium 
meliloti T2c, and strains $\mathrm{f}$ and $\mathrm{j}$ were identified as Serratia proteamaculans T2f, and Stenotrophomonas rhizophila T2j, respectively, based on the similarity of the 16S rRNA gene sequence (Table 3). Serratia and Stenotrophomonas spp. are often reported as being members of biofilm-forming bacteria (Bonaventura et al. 2004, Labbate et al. 2004) and of activated sludge-derived microbial communities (Assih et al. 2002, Du et al. 2008). However, the involvement of these strains in the formation of bacterial aggregates has never been reported previously.

Strains c, f, and j were precultivated in LB medium, and individually inoculated to an MSM containing TuO. However, neither degradation of TuO nor formation of aggregates was observed even after repeated cultivations (data not shown). In contrast, when a mixture of three these strains (named AM) was inoculated to a TuO-containing MSM, bacterial aggregates were formed and these aggregates looked oily (data not shown). However, the rate of TuO degradation by AM was only $18 \%$ at a maximum in seven days (Table 1 ). These results suggest that strains $c, f$, and $\mathrm{j}$ are involved in the formation of bacterial aggregates 
only when these strains coexisted but they are not significantly involved in the degradation of TuO. To induce the formation of aggregates in the PM mixture, in which no aggregates were formed, a block of the aggregate formed in the seventh AM enrichment culture was inoculated to the seventh PM enrichment culture, and the mixture (named the PM $+\mathrm{AM}$ mixture) was cultivated for seven days. This degraded $68 \%$ of the TuO at the third enrichment cultivation (Table 1), and formation of bacterial aggregates was observed (data not shown, but see Fig. 2). The degree of TuO degradation by this AM and PM combined culture was maintained throughout subsequent enrichment steps (Table 1).

\subsection{Characteristics of bacterial aggregates formed by the tank-2 consortium}

The formation of bacterial aggregates is considered to be one of the important factors for TuO degradation by the bacterial consortia. The tank-2 consortium was cultivated in an MSM containing various types of petroleum product to evaluate the relationship between 
the formation of aggregates and the degradation of hydrocarbons. Aggregates were formed in an MSM containing either TuO, EO, the cyclic alkane fraction of TuO, or crude oil as the sole carbon source. However, no aggregates formed, when SQ, PR, or DC were used as the substrate (data not shown). The common structure found in these petroleum products that were involved in the formation of aggregates is polycyclic alkane hydrocarbons. It is known that the crude oil contains polycyclic alkanes (Maki et al. 2008). Bacterial cell aggregation induced by polycyclic alkanes has not been reported previously. However, some isolates from activated sludges form bacterial aggregates, when they are cultivated with some specific xenobiotics, and these bacteria have been used successfully to augment activated sludges for the degradation of xenobiotics (Boon et al. 2000, McClure et al. 1991).

Many aggregate-forming bacteria have been reported to possess a high cell surface hydrophobicity (Liu et al. 2004), which is considered to facilitate the cells adherence to hydrocarbons. Therefore, the cell surface hydrophobicity of the aggregates and free-living cells of the tank-2 consortium was determined by the BATH assay. The hydrophobicity of 
the aggregates and the free-living cell fraction of tank-2 consortium were $77.6 \%$ and $22.4 \%$,

respectively and, thus a high cell surface hydrophobicity of the bacterial aggregates was demonstrated. To the best of our knowledge, the highest reported cell surface hydrophobicity of a bacterium or a bacterial consortium was is $73 \%$ for aerobic bacterial aggregates grown on acetate (Tay et al. 2002). Microorganisms have developed two general strategies to contact with water-insoluble hydrocarbons: (i) specific adhesion mechanisms and (ii) the production of extracellular emulsifying agents, such as biosurfactants (Rosenberg et al. 1992). A high hydrophobicity of the cell surface is such adhesion mechanism, facilitating cells to contact and to uptake hydrocarbons. Therefore, the formation of bacterial aggregates is considered to play an important role in the effective uptake of recalcitrant hydrocarbons in the TuO-degrading consortia. The formation of cell aggregates by the AM mixture was similar to the biofloccules formation by alkanebiodegrading bacterium Rhodococcus erythropolis (NTU-1 strain), which formed aggregates with size ranging 0.1 to $2 \mathrm{~cm}$ in diameter and removed a significantly amount of 
alkanes by biodegradation and physical trapping (Chang et al. 2009). Differently from this strain the AM mixture was scarcely able to degrade TuO.

The consistent degradation of TuO by the PM + AM mixture (Table 1) suggests that strains in the PM mixture also play an important role in the degradation of $\mathrm{TuO}$ in the consortium. It can be speculated that the AM mixture is mainly involved in the formation of bacterial aggregates and the uptake of hydrocarbons inside the consortium, and that strains comprising the PM mixture are involved in the degradation of TuO. Individual AM strains with a high cell hydrophobicity involved in the uptake of hydrocarbons would be distributed on the surface of the bacterial aggregates, and the PM strains would be located inside the aggregates. It is interesting to note that artificial solidification agents, such as calcium oxide, Portland cement, and ash products renders the oil and/or organics accessible to biodegradation, and the solidification process has been shown to increase the biodegradation of organic molecules as much as 20 fold (Von Krosigk 2004). Therefore, AM strains may secrete a compound(s) that solidifies $\mathrm{TuO}$ and accelerates TuO degradation 
by the PM strains.

From our results, it is considered that the bacterial strains of the TuO-degrading bacterial consortium may share roles, with the uptake of hydrocarbons by AM and their degradation by PM (see Fig. 2). To further understand the TuO-degrading mechanisms by bacteria, it is necessary to investigate the structure and formation process of cell aggregates and the factor(s) that induce aggregation of cells.

\section{References}

Assih, E.A., Ouattara, A.S., Thierry, S., Cayol, J. L., Labat, M., Macarie, H., 2002. Stenotrophomonas acidaminiphila sp. nov., a strictly aerobic bacterium isolated from an upflow anaerobic sludge blanket (UASB) reactor. International Journal of Systematic and Evolutionary Microbiology 52, 559-568. 
Bonaventura, G.D., Spedicato, I., D’Antonio, D., Robuffo, I., Piccolomini, R., 2004.

Biofilm formation by Stenotrophomonas maltophilia: Modulation by quinolones, trimethoprim-sulfamethoxazole, and ceftazidime. Antimicrobial Agents and Chemotherapy 48, 151-160.

Boon, N.J., Goris, J., de Vos, P., Verstraete, W., Top, E.M., 2000. Bioaugmentation of activated sludge by an indigenous 3-chloroaniline-degrading Comamonas testosteroni strain I2gfp. Applied and Environmental Microbiology 66, 2906-2913.

Brosius, J., Palmer, J.L., Kennedy, J.P., Noller, H.F., 1978. Complete nucleotide sequence of a 16S ribosomal RNA gene from E. coli. Proceedings of the National Academy of Sciences of the United States of America 75,4801-4805.

Chang, W.N., Liu, C.W., Liu, H.S., 2009. Hydrophobic cell surface and bioflocculation behavior of Rhodococcus erythropolis. Process Biochemistry 44, 955-962.

Du, C., Wu, Z., Xiao, E., Zhou, Q., Cheng, S., Liang, W., He, F., 2008. Bacterial diversity in activated sludge from a consecutively aerated submerged membrane bioreactor treating 
domestic wastewater. Journal of Environmental Sciences 20, 1210-1217.

Ito, H., Hosokawa, R., Morikawa, M., Okuyama, H., 2008. A turbine oil-degrading bacterial consortium from soils of oil fields and its characteristics. International Biodeterioration \& Biodegradation 61, 223-232.

Klappenbach, J.A., Dunbar, J.M., Schmidt, T.M., 2000. rRNA operon copy number reflects ecological strategies of bacteria. Applied and Environmental Microbiology 66, 13281333.

Komiya, K., 1997. Basic physical properties of lubricating oils (composition and physical properties of petroleum). Nesseki Review 39, 135-142 (in Japanese).

Labbate, M., Queck, S.Y., Koh, K.S., Rice, S.A., Givskov, M., Kjelleberg, S., 2004. Quorum sensing-controlled biofilm development in Serratia liquefaciens MG1. Journal of Bacteriology 186, 692-698.

Lappas, A.A., Patiaka, D., Ikonomou, D., Vasalos, I.A., 1997. Separation and characterization of paraffins and naphthenes from FCC feedstocks. Industrial \& 
Engineering Chemistry Research 36, 3110-3115.

Liu, Y., Yang, S.F., Tay, J.H., Liu, Q.S., Qin, L., Li, Y., 2004. Cell hydrophobicity is a triggering force of biograbulation. Enzyme and Microbial Technology 34, 371-379.

Maki, H., Maekawa, K., Okamoto, Y., 2008. A field experiment of Sakhalin Vityaz crude oil degradation at a shore of Saroma Lake, Hokkaido (in Japanese with English summary). Journal of Water and Waste 50, 1005-1011.

McClure, N.C., Fry, J.C., Weightman, A. J., 1991. Survival and catabolic activity of natural and genetically engineered bacteria in a laboratory-scale activated-sludge unit. Applied and Environmental Microbiology 57, 366-373.

Muyzer, G., de Waal, E.C., Uitterlinden, A.G., 1993. Profiling of complex microbial populations by denaturing gradient gel electrophoresis analysis of polymerase chain reaction-amplified genes coding for $16 \mathrm{~S}$ rRNA. Applied and Environmental Microbiology 59, 695-700.

Perry, J.J., 1984. Microbial metabolism of cyclic alkanes. In: Atlas, R.M. (Ed.), Petroleum 
Microbiology. MacMillan Publishing Company, New York, pp. 61-98.

Rosenberg, E., Legmann, R., Kushmaro, A., Taube, R., Ader, E., Ron, E.Z., 1992. Petroleum bioremediation-a multiphase problem. Biodegradation 3, 337-350.

Rosenberg, M., Gutnick, D., Rosenberg, E., 1980. Adherence of bacteria to hydrocarbons: a simple method for measuring cell surface hydrophobicity. FEMS Microbiology Letters 9, 29-33.

Sayler, G.S., Ripp, S., 2000. Field application of genetically engineered microorganisms for bioremediation processes. Current Opinion in Biotechnology 11, 286-289.

Sonderkamp, S., Vomberg, A., Schmitz, C., Fasbender, U., Klinner, U., 2001. Interactions between bacterial populations during degradation of a lubricant base oil. FEMS Microbiology Ecology 38, 97-104.

Tay, J.H., Liu, Q.S., Liu, Y., 2002. Characteristics of aerobic granules grown on glucose and acetate in sequential aerobic sludge blanket reactors. Environmental Technology 23, 931-936. 
Ueno, A., Ito, I., Yamamoto, Y., Yumoto, I., Okuyama, H., 2006. Bacterial community change analysis of diesel oil-contaminated soil microcosms biostimulated with LuriaBertani medium and bioaugmented with a petroleum-degrading bacterium, Pseudomonas aeruginosa strain WatG. Journal of Basic Microbiology 46, 310-317.

Von Krosigk, J.R., 2004. Composition for oil and gas drilling fluids with solidification agent and cellulose additive. US Patent 6,797,675.

Wongsa, P., Tanaka, M., Ueno, A., Hasanuzzaman, M., Yumoto, I., Okuyama, H., 2004. Isolation and characterization of novel strains of Pseudomonas aeruginosa and Serratia marcescens possessing high efficiency to degrade gasoline, kerosene, diesel oil, and lubricating oil. Current Microbiology 49, 415-422. 
Figure legends

Fig. 1. DGGE band profiles of the tank-2 consortium and 14 isolates (strain a to strain n)

(A), and those of the tank-2 consortium (lane 1) and the IM mixture (lane 2), and cell aggregates (lane 3) and free-living cell fraction (lane 4) of the tank-2 consortium (B). In (A), the fifty third enrichment tank-2 consortium was used. Isolated strains were cultivated in 2 $\mathrm{ml}$ of $\mathrm{LB}$ medium in a test tube at $30{ }^{\circ} \mathrm{C}$ for one day on a rotary shaker (160 rpm). In (B), cells of the IM mixture (a mixture of all isolates from the tank-2 consortium) were harvested from the fourth enrichment culture. The cells of the fifty ninth tank-2 consortium were separated into cell aggregates and a free-living cell fraction, as described in the Materials and Methods section. As a control the fifty eighth enrichment tank-2 consortium was used. An amount of $300 \mu$ g of DNA was loaded in each lane. The gradient shown in the figure denotes a denaturant urea-formamide gradient ranging from $20 \%$ to $60 \%$. 
Fig 2. A possible structure of the bacterial aggregates formed in the tank-2 consortium and the roles of aggregates and free-living bacteria in the degradation of TuO. Bacterial cells with a high cell surface hydrophobicity (AM) and free-living bacteria (PM) are involved in cell aggregate formation and TuO degradation, respectively. The inserted photo shows the seventh PM + AM enrichment culture in flask. 
Table 1

Effects of the repeated enrichment processes on the degradation of turbine oil (TuO) by tank-2 consortium and various types of artificial mixture of strains isolated from the tank-2 consortium.

\begin{tabular}{cccccccc}
\hline \multirow{2}{*}{ Enrichment } & First & Second & Third & Fourth & Fifth & Sixth & Seventh \\
\cline { 2 - 7 } & \multicolumn{5}{c}{ TuO degradation (\%) } \\
& & \multicolumn{5}{c}{ (\% } & \\
Tank-2 consortium $^{\mathrm{a}}$ & $16 \pm 8$ & $74 \pm 10$ & $75 \pm 6$ & $84 \pm 3$ & $86 \pm 5$ & $88 \pm 4$ & $88 \pm 3$ \\
Artificial mixtures & & & & & & \\
IM & $6 \pm 4$ & $7 \pm 3$ & $61 \pm 2$ & $65 \pm 8$ & $29 \pm 13$ & $15 \pm 2$ & $15 \pm 9$ \\
PM & $3 \pm 2$ & $20 \pm 8$ & $46 \pm 13$ & $62 \pm 4$ & $50 \pm 15$ & $28 \pm 13$ & $30 \pm 10$ \\
AM & $5 \pm 1$ & $12 \pm 5$ & $14 \pm 3$ & $18 \pm 6$ & $14 \pm 2$ & $18 \pm 7$ & $18 \pm 4$ \\
PM + AM & $7 \pm 4$ & $42 \pm 12$ & $68 \pm 2$ & $65 \pm 4$ & $68 \pm 5$ & $62 \pm 4$ & $67 \pm 1$ \\
\hline
\end{tabular}

${ }^{\text {a }}$ The tank-2 consortium was established as described in the section of Materials and methods. To measure the degradation of $\mathrm{TuO}$ a small block of these bacterial aggregates (approximately $2 \mathrm{~mm} \times 4 \mathrm{~mm} \times 1 \mathrm{~mm}$ ) and $200 \mu \mathrm{l}$ of liquid culture of the tamk-2 enrichment cultures were transferred to $10 \mathrm{ml}$ MSM supplemented with $0.5 \%$ (w/v) TuO in a $50 \mathrm{ml}$ flask. After shaken at $160 \mathrm{rpm}$ at $30{ }^{\circ} \mathrm{C}$ for five days, the residual TuO was quantified.

b The IM and PM are mixtures of all 14 strains and four predominant strains (strains d, e, $\mathrm{g}$, and $\mathrm{m}$ ), respectively, isolated from the tank-2 consortium and the AM is a mixture of three strains (strains c, $\mathrm{f}$, and $\mathrm{j}$ ) isolated from the cell aggregates formed in the tank-2 consortium (see Figs. 1 and 2 and Table 2). The PM + AM is a mixture of PM and AM. In the enrichment cultivations of IM, PM, and AM mixtures, individual constituent 
strains were cultivated in LB medium at $30{ }^{\circ} \mathrm{C}$ for one day. Mixed cultures (inocula) were transferred to MSM containing $0.5 \%(w / v) ~ T u O$. The initial $\mathrm{OD}_{600}$ of the inocula was set at 0.1 . These cultures were incubated at $30{ }^{\circ} \mathrm{C}$ with shaking at $160 \mathrm{rpm}$ for one week (the first enrichment cultures). As the AM mixture cells formed aggregates in TuO-containing MSM, only a block of aggregates was used as inoculum for the subsequent enrichments. In the enrichment process of the PM $+\mathrm{AM}$ mixture, the seventh PM (200 $\mu$ l) and AM (a small block of aggregates) enrichment cultures were inoculated to MSM containing $0.5 \%(\mathrm{w} / \mathrm{v}) \mathrm{TuO}$ and incubated as described above (the first enrichment culture of the PM + AM). In the subsequent enrichment a liquid culture (200 $\mu \mathrm{l})$ and a block of aggregates of the PM + AM enrichment culture were transferred to a fresh medium. The degradation test of TuO was performed as described above, but incubation was done for seven days.

The degradation rate of TuO was shown as means \pm standard errors for three independent experiments. 
Table 2

Strains from the tank-2 consortium and types of agar plates and petroleum products used for isolation.

\begin{tabular}{|c|c|c|c|}
\hline \multirow[t]{2}{*}{ Strain } & \multicolumn{2}{|c|}{$\begin{array}{c}\text { Combination of agar plate and petroleum } \\
\text { product for the isolation of strains }\end{array}$} & \multirow{2}{*}{$\begin{array}{c}\text { Bands detected in } \\
\text { the tank-2 } \\
\text { consortium }\end{array}$} \\
\hline & Agar plate & Petroleum product overlayer & \\
\hline a & $\mathrm{LB}$ & none & 4,5 \\
\hline $\mathrm{b}$ & LB & none & None \\
\hline c & LB & $\mathrm{TuO}$ & 10 \\
\hline $\mathrm{d}$ & LB & $\mathrm{TuO}$ & None \\
\hline e & LB & $\mathrm{TuO}$ & 1,9 \\
\hline $\mathrm{f}$ & LB & DC & 8 \\
\hline g & LB & DC & $3,4,5$ \\
\hline $\mathrm{h}$ & LB & PR & 7 \\
\hline $\mathrm{i}$ & LB & Cyclic alkane fraction of TuO & None \\
\hline $\mathrm{j}$ & LB & Cyclic alkane fraction of TuO & 6 \\
\hline $\mathrm{k}$ & MSM & $\mathrm{TuO}$ & 11 \\
\hline 1 & MSM & $\mathrm{TuO}$ & None \\
\hline $\mathrm{m}$ & MSM & $\mathrm{TuO}$ & $3,4,5,12$ \\
\hline $\mathrm{n}$ & MSM & crude oil & None \\
\hline
\end{tabular}

The number in the right-hand column is that of the band detected in the DGGE analysis of the fifty third enrichment tank-2 consortium. MSM, minimal salt medium; TuO, turbine oil; DC, dodecylcyclohexane; and PR, 
pristine, (2,6,10,14-tetramethylpentadecane). 
Table 3

Tentative identification of strains in the PM and AM mixtures from the tank-2 consortium based on their 16S rRNA gene sequences.

Tentative identification

Strain Closest identified strain (\% identity)

(Accession no.)

Strains in the PM mixture

d Pseudomonas putida strain BN-St Pseudomonas putida T2d

$(99 \%)$

(AB539808)

e Pseudomonas putida strain QstW3 Pseudomonas putida T2e

$(98 \%)$

(AB539809)

g Pseudomonas putida strain Ok-St Pseudomonas putida T2g

$(99 \%)$

(AB539810)

m Pseudomonas putida strain JM9 (99\%) Pseudomonas putida T2m

(AB539811)

Strains in the AM mixture

c $\quad$ Sinorhizobium meliloti 1021 (98\%) Sinorhizobium meliloti T2c

(AB539807)

f $\quad$ Serratia proteamaculans 568 (99\%) Serratia proteamaculans T2f

(AB539812)

j Stenotrophomonas rhizophila strain Stenotrophomonas rhizophila T2j Asd M1-7 (98\%) (AB539813)

All of the sequences of isolates were identified by the GenBank Blast search (http://www.ncbi.nlm.nih.gov/BLAST). 
Fig. 1A

Tank-2 consortium

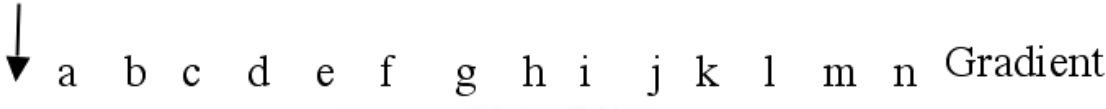

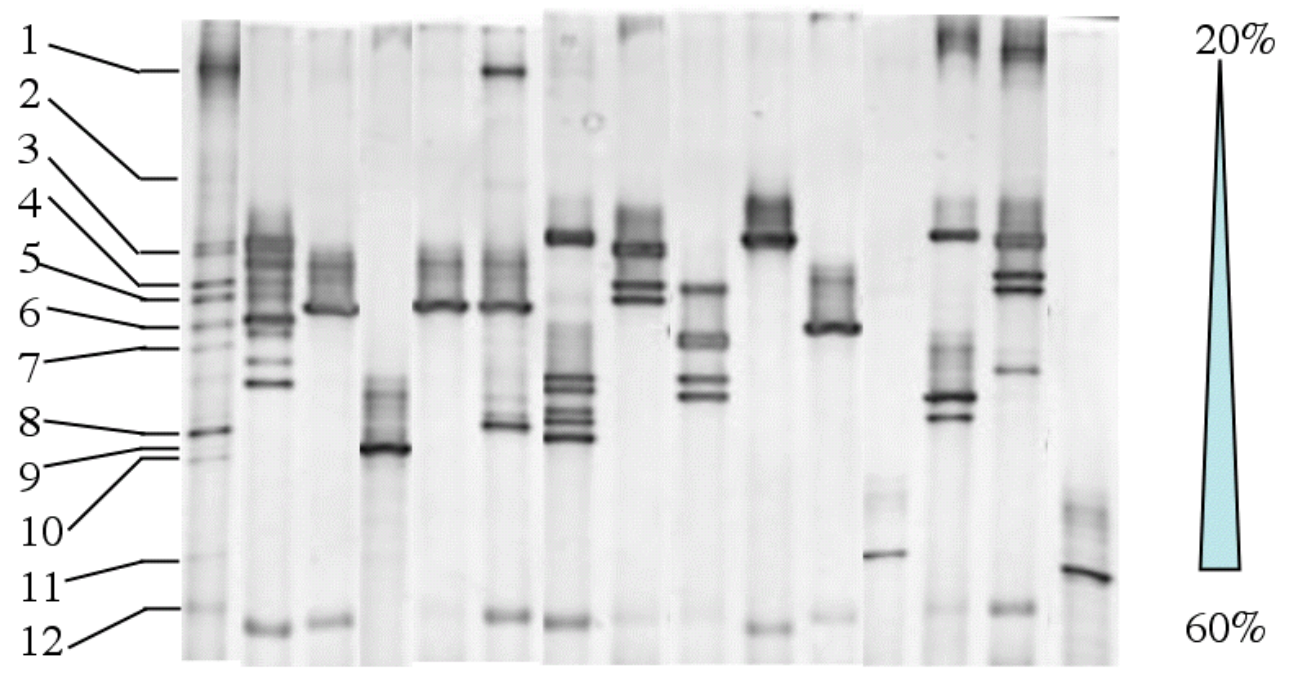

Fig. 1B

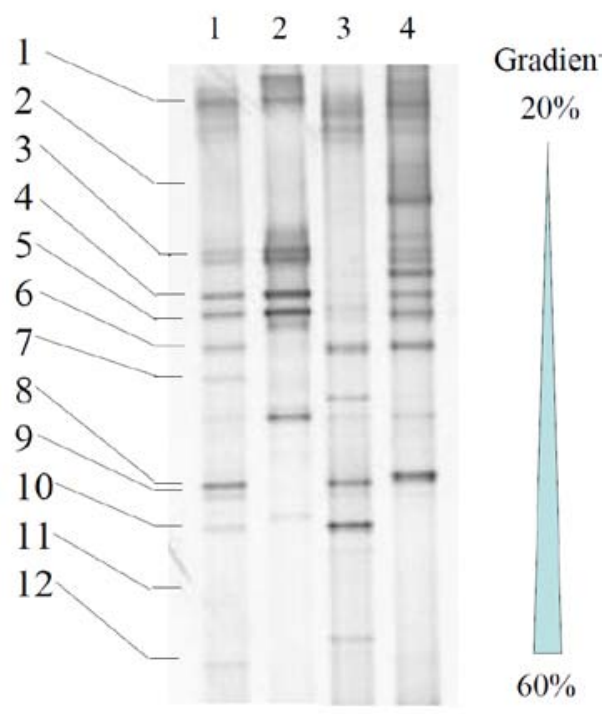


Fig. 2.

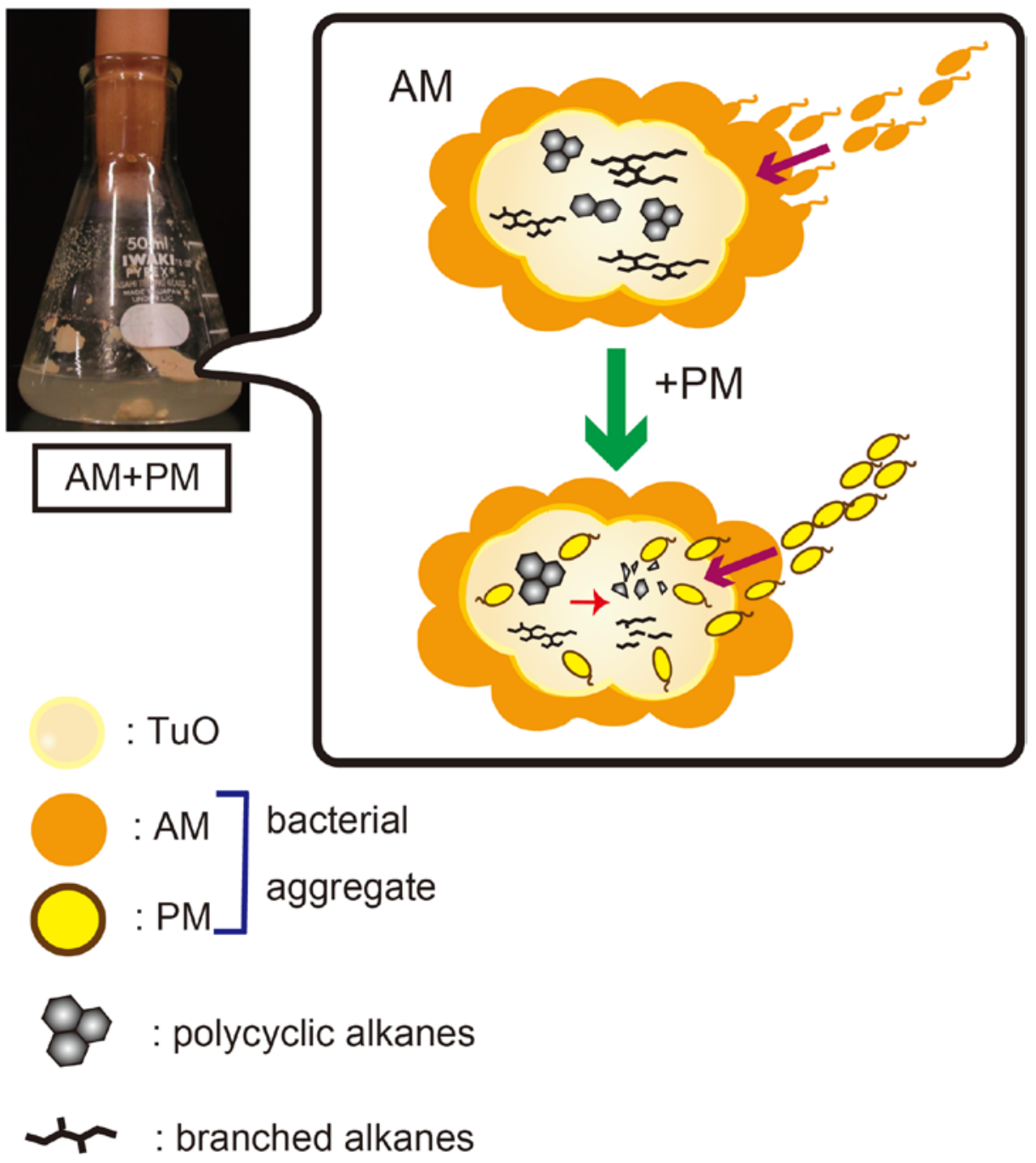

